\title{
Migraine and its psychiatric comorbidities
}

\author{
Mia Tova Minen, ${ }_{1}^{1}$ Olivia Begasse De Dhaem, ${ }^{2}$ Ashley Kroon Van Diest, ${ }_{1}^{3}$ \\ Scott Powers, ${ }^{4}$ Todd I Schwedt, ${ }^{5}$ Richard Lipton, ${ }^{6}$ David Silbersweig ${ }^{7}$
}

${ }^{1}$ Department of Neurology, NYU Langone Medical Center, New York, New York, USA ${ }^{2}$ Department of Internal Medicine, NYU Langone Medical Center, New York, New York, USA

${ }^{3}$ Division of Behavioral Medicine and Clinical Psychology, Cincinnati Children's Medical Center, Cincinnati, Ohio, USA ${ }^{4}$ Cincinnati Children's Medical Center, Headache Center, Office for Clinical and Translational Research, Center for Child Behavior and Nutrition Research and Training, Pediatrics, Cincinnati, Ohio, USA

${ }^{5}$ Department of Neurology, Mayo Clinic, Phoenix, USA

${ }^{6}$ Department of Neurology, Albert Einstein College of Medicine, Bronx, New York USA

${ }^{7}$ Department of Psychiatry, Brigham and Women's Hospital, Boston,

Massachusetts, USA

\section{Correspondence to} Dr Mia Tova Minen, Department of Neurology, NYU Langone Medical Center, 240 East 38th Street 20th floor, New York, NY 10016, USA; minenmd@gmail.com

Received 11 September 2015 Revised 11 November 2015 Accepted 26 November 2015 Published Online First 5 January 2016

\section{CrossMark}

To cite: Minen MT, Begasse De Dhaem O, Kroon Van Diest A, et al. J Neurol Neurosurg Psychiatry 2016;87:741-749.

\section{ABSTRACT}

Migraine is a highly prevalent and disabling neurological disorder associated with a wide range of psychiatric comorbidities. In this manuscript, we provide an overview of the link between migraine and several comorbid psychiatric disorders, including depression, anxiety and post-traumatic stress disorder. We present data on psychiatric risk factors for migraine chronification. We discuss the evidence, theories and methods, such as brain functional imaging, to explain the pathophysiological links between migraine and psychiatric disorders. Finally, we provide an overview of the treatment considerations for treating migraine with psychiatric comorbidities. In conclusion, a review of the literature demonstrates the wide variety of psychiatric comorbidities with migraine. However, more research is needed to elucidate the neurocircuitry underlying the association between migraine and the comorbid psychiatric conditions and to determine the most effective treatment for migraine with psychiatric comorbidity.

\section{INTRODUCTION}

Migraine affects $12 \%$ of adults in the USA, making this condition a common concern for many patients and their doctors. ${ }^{1}$ Often overlooked is the high prevalence of psychiatric comorbidities associated with migraine, such as depression, anxiety and post-traumatic stress disorder. ${ }^{2-4}$ Migraineurs with psychiatric comorbidity have higher healthcare utilisation tendencies than migraineurs without psychiatric comorbidity. ${ }^{5}$ If left untreated, these comorbid psychiatric conditions can increase the risk of migraine chronification, the evolution of episodic migraine (EM) into chronic migraine (CM) (ie, at least 15 headache days a month, including at least 8 days/month with full-blown migraines). In addition, if left untreated, the comorbid psychiatric conditions can increase migraine-related disability, reduce quality of life and negatively impact treatment outcomes.

Here, we describe the epidemiology of psychiatric comorbidities associated with migraine, and describe some screening tools for diagnosing these comorbidities. Following this, we describe recent functional neuroimaging findings and theories that might help to elucidate the connection. We then provide an overview of migraine treatment options, including pharmacological and behavioural therapies with a special emphasis on treating patients with psychiatric comorbidities.

\section{PSYCHIATRIC COMORBIDITIES ASSOCIATED \\ WITH MIGRAINE \\ Depression}

Psychiatric comorbidities are common in migraine patients (table 1).

Depression is one of the most common psychiatric comorbidities in patients with migraine. Three different studies found that migraineurs are over 2.5 times more likely to suffer from depression compared with non-migraineurs. ${ }^{6-8} \mathrm{~A}$ meta-analysis of data from 12 studies on migraine and depression found that the incidence of depression in migraineurs is highly variable, ranging from $8.6 \%$ to $47.9 \% .^{9}$

The association between migraine and major depressive disorder is even stronger for patients with CM and for patients who have migraine with aura. ${ }^{10}$ The relationship between migraine and depression appears to be bidirectional. ${ }^{7}$

There is no current evidence that improved control of depression helps to control migraines. However, it is important to identify and treat depression in patients with migraine because it is a significant predictor of migraine chronification. ${ }^{10}$ Furthermore, migraineurs who suffer from depression are more likely to be refractory to migraine treatments and to suffer from medication overuse and disability. ${ }^{11}$

The efficacy of tricyclic antidepressants in prevention of migraine suggests a shared causative mechanism for depression and migraine. ${ }^{12}$ The current hypotheses to explain this shared causative mechanism include serotonergic dysfunction, hormonal influences and sensitisation of the sensory and emotional neural networks. ${ }^{13}$

\section{Bipolar spectrum disorder}

There seems to be a bidirectional relationship between migraine and bipolar disorder. Patients suffering from migraine with aura are three times more likely to suffer from bipolar disorder than the general population. ${ }^{14-16}$ Conversely, about one-third of patients with bipolar disorder have migraine. The prevalence of migraine was higher among people with bipolar disorder type II (54.17\%, 95\% CI 31.52 to 75.95$)$ compared with bipolar disorder type I $(32.7 \%$, 95\% CI 18.16 to 49.19). ${ }^{17}$

Bipolar disorder comorbidity with migraine seems to be a subtype of bipolar disorder with an unstable rapid cycling course, an increased prevalence of comorbid panic attacks, an earlier age of onset and increased prevalence in women. ${ }^{18} 19$

Bipolar disorder and migraine share similar features. They are both episodic, worsened by stress, associated with a family history of affective disorders 
Table 1 Prevalence of common psychiatric comorbidities in patients with migraine

\begin{tabular}{ll}
\hline Psychiatric comorbidities & $\begin{array}{l}\text { Percentage of patients with migraine } \\
\text { cited to have the comorbidity }\end{array}$ \\
\hline Depression & $41-47^{67}$ \\
Anxiety & $51-58^{25}$ \\
Post-traumatic stress disorder & $9-43^{54} 55$ \\
Childhood trauma & $58^{128}$ \\
Abuse during adulthood & $33^{128}$ \\
\hline
\end{tabular}

and migraine, and responsive to anticonvulsants such as valproate. ${ }^{20}$ Although there is still much to learn about the neurobiology of both disorders, they are thought to share a common pathophysiology involving dysfunction of calcium channels. ${ }^{18}$

\section{Anxiety disorders}

More than half of the patients with migraine will meet the criteria for at least one anxiety disorder in their lifetime. Anxiety disorders are two to five times more prevalent in patients with migraine than in the general population, up to two times more common in patients with migraine than in patients with depression, and much more common in patients with CM than in patients with EM. ${ }^{21}$ Depression is often comorbid, with anxiety disorders in patients with migraine. ${ }^{22}$ Among the anxiety disorders, generalised anxiety disorder (GAD), obsessive compulsive disorder (OCD) and panic disorder (PD), are the most strongly linked with migraine. ${ }^{22}$

Patients with GAD are at increased risk for migraine (OR 3.86 , 95\% CI 2.48 to 6), and patients with migraine are at increased risk for GAD (OR 3.13, 95\% CI 1.56 to 6.3 ). ${ }^{23}$

Patients with OCD are at increased risk and higher frequency of migraine (OR 4.57, 95\% CI 2.82 to 7.83 for migraine 2-6 times/week). ${ }^{24}$ The OR of PD in migraine is 3.76 , and is even greater in patients with migraine with aura. ${ }^{25} \mathrm{PD}$ is associated with increased migraine frequency, increased disability, higher risk of chronification and higher risk of medication overuse. ${ }^{25}$ Migraine and PD share features such as functional impairment, gastrointestinal (nausea), autonomic (dizziness), affective (fear) symptoms during attacks, and worry about further attacks between attacks. $^{25}$

Patients with migraine with a comorbid anxiety disorder spend US\$4634 more per year in healthcare than those without comorbid anxiety. ${ }^{26}$ One study found that a family history of anxiety was associated with self-reported usage of nonpharmacological treatments for headache. However, most of the participants in non-pharmacological treatments who reported such use, were not those with grade A evidence. ${ }^{27}$ Controlling anxiety of patients with migraine is associated with improved quality of life, adherence to a migraine treatment plan, and effectiveness of migraine treatment. ${ }^{22}$

The relationship between anxiety disorders and migraine seems to be bidirectional. ${ }^{25}$ Both anxiety and migraine have been associated with a higher frequency of the s allele in a study of the 5HTTLPR polymorphism of the serotonin transporter gene, implying a common genetic predisposition. ${ }^{28}$ Current hypotheses on the neurobiological mechanism underlying the association between anxiety and migraine include serotonergic dysfunction, dysregulation of the hypothalamic-pituitary-adrenal (HPA) axis, hormonal influences and psychological factors, such as interoceptive conditioning, pain-related cognition, avoidance learning and anticipatory anxiety. ${ }^{25} 29$
Stress

Stress is a prevalent migraine trigger. Patients with migraine tend to suffer from high levels of stress, especially those with CM. ${ }^{30}$ The Frequent Headache Epidemiology Study suggested that patients with CM had more major life events in the year preceding the chronification of their migraines than did patients with EM. ${ }^{31}$ The Longitudinal Brazilian study (ELSA-Brasil) showed an association between negative life events and increased frequency of migraine. ${ }^{32}$ Stress management with relaxation therapies, biofeedback and cognitive behavioural therapies were proven to be effective migraine prophylaxis measures. $^{33-37}$

Chronic repeated stress (including repeated migraines) leads to allostatic dysfunction, manifested as both structural and functional damage. ${ }^{38} 39$ These negative changes impact pain processing, induce central sensitivity, and might affect the pain experience in patients with migraine. ${ }^{33} 39$ In response to a painful heat stimulus, patients with migraine have more activation on their functional MRI (fMRI) studies in the perigenual cortex than patients without migraine, which was found to be the brain area associated with allostatic dysfunction in rats. ${ }^{40}$ The overuse of analgesic and headache symptomatic medications might affect allostasis too. Patients with CM with medication overuse were found to have impaired secretion of the growth hormone, ACTH and cortisol. ${ }^{41}$ The degree of endocrine dysfunction seemed to be correlated to the duration of the CM. ${ }^{41}$

In addition, stress reduction is associated with increased risk of migraine the following day, which could support the biological associations between stress and headaches discussed above. $^{42}$ Indeed, stressors activate the autonomic nervous and neuroendocrine systems, which leads to increased glucocorticoids, and hence, anti-inflammatory and antinociceptive effects. These processes are reversed when the stress ends, which could precipitate a migraine. $^{42}$

Stress also affects psychiatric disorders. Stressful events, especially early in life, increase the incidence and susceptibility of major depressive disorder and other psychiatric disorders. Chronic stress early in life and in adulthood can decrease the expression of glucocorticoid receptors (GR) upregulate the expression of the cochaperone gene, FKBP5, which restrains GR activity by limiting the translocation of the receptor complex to the nucleus, and alter transcriptional activity. As a result, chronic stress can impact gene function, response to future stressors and susceptibility to further stressors, migraine, and psychiatric disorders. ${ }^{43}$

\section{Abuse and post-traumatic stress disorder}

Migraine is more prevalent in patients with a history of emotional abuse, physical abuse, physical neglect and/or sexual abuse compared with the general population (OR 1.6-1.8). ${ }^{44}$ This association is maintained independently of comorbid depression and/or anxiety in the case of emotional abuse. ${ }^{45}$ Childhood emotional abuse is a risk factor for migraine chronification, more disabling migraines, allodynia and earlier onset of migraines. ${ }^{46}$ There appears to be an association between the number of adverse childhood events (ACE score) and migraine frequency. ${ }^{44}$ Patients with headache with a history of emotional abuse, emotional neglect and/or sexual abuse are more likely to suffer from migraines than tension headaches. ${ }^{45}$ One hypothesis for the association between abuse and migraine involves cortisol dysfunction and stress reactivity. Perhaps past abuse modifies the HPA axis leading to greater stress reactivity and migraine. ${ }^{47} 48$

However, recent studies suggest that abuse is not independently associated with migraine, and that post-traumatic stress 
disorder (PTSD) mediates the association. A cross-sectional study that compared patients with and without migraine showed that PTSD (OR 2.3, 95\% CI 1.56 to 3.39), but not trauma alone (OR $1.17,95 \%$ CI 0.85 to 1.61 ), is a predictor of migraine. ${ }^{25}$ In veterans, PTSD is associated with increased consumption of prescription medications for headaches (used as a marker of headache), more in men (OR 5.2 with $95 \%$ CI 2.4 to 11.1) than in women (OR 2.0 with 95\% CI 1.1 to 3.7). No associations were found between either lifetime or combat traumatic events and use of prescription medication for headaches. ${ }^{49}$

Persons with headache and a history of abuse or neglect are more likely to have migraine than tension-type headache warranting an increased index of diagnostic suspicion for migraine. Knowledge of abuse and neglect makes it more likely that headaches are attributable to migraine. In addition, the psychological consequences of abuse and its sequelae, including PTSD and depression, are important treatable comorbidities of migraine. This is especially important because migraineurs with PTSD were found to have greater disability and more lost work days due to physical or mental health or substance abuse ( 8 days for migraineurs with PTSD compared with 2.6 days for migraineurs without PTSD, adjusted rate ratio 2.77 (95\% CI 2.45 to 3.14)), and more difficulties with developing and maintaining a social life than migraineurs without PTSD (adjusted OR 2.32 (95\% CI 1.15 to 4.09$)$ ). ${ }^{50}{ }^{51}$ Cognitive-behavioural therapy (CBT) for PTSD was found to improve the disability of patients with migraine with comorbid PTSD. ${ }^{52}$

PTSD is much more prevalent in patients with migraine than in the general population (14-25\% vs $1-12 \%)$, and is even more prevalent in patients with $\mathrm{CM}$ compared with patients with EM (43\% vs 9\%), despite a similar frequency and prevalence of trauma exposure between the groups. ${ }^{53-55}$ Patients with migraine have increased lifetime and 1 year ORs of PTSD compared with the general population. ${ }^{56}$ On the one hand, PTSD increases the risk of migraine development. ${ }^{56}$ On the other hand, patients with migraine might suffer from increased allostatic loads and subsequent maladaptive stress responses, which might predispose them to PTSD. ${ }^{56}$ Current hypotheses on neurobiological mechanism underlying the association between PTSD and migraines include serotonergic, autonomic nervous system, and HPA axis dysfunction. This would also explain why both PTSD and migraine have mood and anxiety disorder comorbidities. 57

\section{Adult attention deficit hyperactivity disorder}

There is extremely limited data on migraine and attention deficit hyperactivity disorder (ADHD). A cross-sectional study reported an increased prevalence of migraine in patients with persistent ADHD compared with the general population (OR $1.67,95 \%$ CI 1.28 to 2.17$).{ }^{58}$ Of note, comorbid depression and anxiety were more prevalent in patients with persistent ADHD suffering from migraines than in those without migraines. $^{58}$

\section{Sleep}

Sleep disorders are more prevalent in patients with migraine than in the general population. ${ }^{59}$ The Third Nord-Trondelag Health Study showed an increased risk of severe sleep disturbances as measured by the Karolinska Sleep Questionnaire and the Epworth Sleepiness Scale with migraine (OR 5.4, 95\% CI 2 to 14.5$){ }^{60}$ More than half the patients with migraine report sleep difficulties at least occasionally, and more than a third of them suffer from frequent sleep difficulties and chronic short sleep ( $\leq 6 \mathrm{~h}$ per night). ${ }^{61}$ Chronic short sleep was found to be associated with more severe headaches. ${ }^{61}$ In terms of sleep diagnoses, migraine is associated with a wide variety of sleep disorders, such as restless leg syndrome, parasomnias, sleep apnoea and insomnia. ${ }^{62} \mathrm{~A}$ small randomised placebo-controlled trial showed significant improvement in headache frequency and severity, and sometimes even a reversal from CM to EM in patients who underwent behavioural sleep modification compared with a placebo intervention. ${ }^{63}$ Controlling a patient's sleep apnoea was found to have a positive effect on their chronic migraines. $^{59}$

The relationship between migraines and sleep is bidirectional: on the one hand, sleep disturbances (such as, excess of, lack of, or irregular sleep) are known triggers and risk factors for migraines, and on the other hand, migraines interfere with patients' quality of sleep. ${ }^{64}$ The neurobiological mechanism underlying this relationship is likely due to some overlapping pathophysiology and shared anatomical structures within the brain. ${ }^{65}$ In addition, depression and anxiety are comorbid with both sleep disorders and migraine.

\section{Substance abuse}

Prior studies have suggested an association between migraine and increased risk of substance abuse and addiction. ${ }^{66} 67 \mathrm{~A}$ study showed that $19 \%$ of opioid-dependent patients started opioids because of headache. ${ }^{68}$ However, this association was not found in later studies. ${ }^{69}$ The association between migraine and substance abuse was no longer statistically significant in the analysis of the National Comorbidity Survey Replication data when adjusting for the depression, and PTSD confounders. ${ }^{56}$

There is no known association between alcohol use disorder and migraine. In a large population-based study, the 12-month prevalence of alcohol dependence measured by the World Mental Health Composite International Diagnostic Interview was similar among migraineurs and controls. ${ }^{3}$ In a crosssectional study, migraineurs consumed less alcohol than controls ( 2.34 vs 2.92 drinks per week, $p=0.038$ ); these findings may be explained by the fact that alcohol is a headache trigger in $37.8 \%$ of migraineurs and a consistent trigger in $10 \%$ of migraineurs. ${ }^{70}$ In addition, migraineurs have a lower alcoholic beverage threshold for alcohol-delayed headache. The relationship between alcohol and headaches is thought to be mediated by the 5 -hydroxytryptamine system. ${ }^{71}$

\section{Personality disorders}

The diagnoses of personality disorders remain a matter of debate in the psychiatric community. The Diagnostic and Statistical Manual of Mental Disorders (DSM)-V does not have an axis II anymore; however, the 10 diagnoses of personality disorders were retained, although the decision to keep them is not widely accepted. Furthermore, the pathophysiology of personality disorders is still unknown. Thus, personality disorders are beyond the scope of this review. ${ }^{72}$

\section{SCREENING TOOLS FOR PSYCHIATRIC COMORBIDITIY}

Screening for comorbid psychiatric disorders in persons with migraine has been recommended. ${ }^{73}$ A number of instruments are also available to screen for general psychiatric symptoms and specific conditions, such as depression, anxiety and bipolar disorder (see table 2 for a detailed list of screening tools). Screening is especially important if patients or families report symptoms of depression and anxiety, or if the clinician observes dysphoric or anxious moods. ${ }^{73} 74$ While some have advocated verbal screening with informal questions (eg, 'Do you feel depressed?', 'Do you worry frequently?'), ${ }^{75}$ we prefer the use of 
Table 2 Screening tools

\begin{tabular}{|c|c|c|}
\hline Condition & Screen & Comments \\
\hline \multicolumn{3}{|l|}{ Migraine-specific screening tools } \\
\hline Migraine Related Disability & Migraine Disability Assessment Scale (MIDAS) ${ }^{129} 130$ & Most global validated scale for measuring migraine disability outcomes \\
\hline \multicolumn{3}{|l|}{ Non-migraine-specific screening tools } \\
\hline $\begin{array}{l}\text { Psychiatric Comorbidity Transdiagnostic } \\
\text { Symptoms }\end{array}$ & $\begin{array}{l}\text { Mood, Anxiety and Physical Symptom Scale (MAPSS) } \\
\text { Hospital Anxiety and Depression Scale (HADS) } \\
\text { H11 } 132\end{array}$ & $\begin{array}{l}\text { Screening for distinctive psychiatric categories is difficult due to the } \\
\text { symptom overlap between the different psychiatric categories } \\
\text { The MAPSS addresses this problem and was field tested in patients } \\
\text { with headache. However, it is not a validated screening tool, and } \\
\text { thus, its utility is limited at this time } \\
\text { Screens for both depression and anxiety }\end{array}$ \\
\hline Depression & $\begin{array}{l}\text { Patient Health Quality (PHQ)-9 } 9^{76} 77 \\
\text { Beck Depression Inventory-2 (BDI-2) }\end{array}$ & $\begin{array}{l}\text { PHQ-9 is completed by the patient and was developed for use in } \\
\text { primary care }\end{array}$ \\
\hline Panic Disorder & Anxiety Sensitivity Index ${ }^{134}$ & \\
\hline Anxiety & $\begin{array}{l}\text { Generalised Anxiety Disorder (GAD) }-7^{135} \\
\text { Beck Anxiety Index (BAI) }\end{array}$ & \\
\hline Bipolar Disorder & Mood Disorders Questionnaire (MDQ) $)^{137} 138$ & \\
\hline Stress & Perceived Stress Scale 139140 & Used in migraine studies \\
\hline Sleep & $\begin{array}{l}\text { Pittsburgh Sleep Quality Index, }{ }^{141} \text { Insomnia Severity } \\
\text { Index }\end{array}$ & $\begin{array}{l}\text { Unless the historical or examination findings suggest a primary sleep } \\
\text { disorder, a formal sleep evaluation is usually not necessary in patients } \\
\text { with a well-defined primary headache diagnosis }{ }^{65}\end{array}$ \\
\hline Post-traumatic Stress Disorder & $\begin{array}{l}\text { Post-traumatic Stress Disorder Checklist (PCL) } \\
\text { Primary care PTSD Screen (PC-PTSD) } \\
1^{143}\end{array}$ & \\
\hline
\end{tabular}

the four depression and anxiety questions from the Patient Health Questionnaire (table 2). ${ }^{76} 77$ Patients who present to headache specialty clinics, and/or patients who are unsuccessful with standard treatment, often warrant more detailed assessment for psychiatric comorbidities. ${ }^{78}$

\section{PSYCHIATRIC COMORBIDITY AND THE RELATIONSHIP WITH MIGRAINE CHRONIFICATION}

Longitudinal studies have demonstrated that in persons with EM, CM develops at the rate of about $2 \%$ to $3 \%$ per year. ${ }^{79}$ The development of CM and its rate of onset in patients with EM are associated with a number of risk factors, including depression and anxiety, stressful life events, snoring, obesity, comorbid pain disorders and overuse of medication. ${ }^{10} 303145$ Depression was a significant predictor of onset of $\mathrm{CM}$ $(\mathrm{OR}=1.65,95 \%$ CI 1.12 to 2.45$)$, after adjusting for sociodemographic variables and characteristics of headache. ${ }^{10}$ Additionally, risk of CM onset increased with depression severity. Relative to study respondents with none or mild depression, those with moderate $(\mathrm{OR}=1.77,95 \% \mathrm{CI} 1.25$ to 2.52$)$, moderately severe $(\mathrm{OR}=2.35,95 \% \mathrm{CI} 1.53$ to 3.62$)$ and severe depression ( $\mathrm{OR}=2.53$, 95\% CI 1.52 to 4.21$)$ were at increased risk for the onset of $\mathrm{CM}$ at increasingly higher rates. ${ }^{10} 79 \mathrm{On}$ the contrary, psychiatric comorbidities are more prevalent in $\mathrm{CM}$ than in EM. ${ }^{80} 81$

Current hypotheses on the neurobiological mechanism underlying the contribution of depression and anxiety to progression of migraine include shared dysfunction of the serotonergic system, overuse of medication derived from a lack of appropriate coping behaviours, and inherent ideology that magnifies pain and unpleasant associated features. ${ }^{82}$

\section{THEORIES AND EVIDENCE UNDERLYING THE RELATIONSHIP BETWEEN MIGRAINE AND PSYCHIATRIC COMORBIDITIES}

There are four general categories for explanation of comorbidity. ${ }^{83}$ First, there may be a unidirectional causal relationship among disorders. For example, if recurrent unpredictable attacks of headache lead to depression as the sole explanation of comorbidity, we would predict that persons with migraine would be at increased risk for depression, but that depression would not be a risk factor for migraine. Available data demonstrates a bidirectional relationship between migraine and depression; persons with either disorder are predisposed to the other, undermining the unidirectional causal explanation. Second, migraine may be comorbid due to a common environmental risk factor. For example, if head injury predisposed both to migraine and anxiety, the link between them could be accounted for by this exposure. Third, migraine may be linked to psychiatric comorbidities through a shared genetic risk factor. ${ }^{15}$ Finally, other biological, environmental or genetic risk factors may converge to produce a brain state which predisposes to both disorders. 9 For example, serotonergic dysfunction, HPA hyperactivity and inflammation could predispose both to migraine and psychiatric comorbidities such as depression. Several systems seem to be involved in the intrinsic relationships between migraines and psychiatric comorbidities, such as stress, insomnia, serotonergic dysfunction, HPA axis hyperactivity, inflammation, hormonal influences, central sensitivity/sensitisation of the sensory and emotional neural networks, and shared genetic risk factors. On the one hand, frequent migraines add to the allostatic load which eventually leads to allostatic dysfunction and central sensitivity. On the other hand, chronic stress, subsequent allostatic dysfunction and central sensitivity predispose to both migraines and psychiatric disorders, such as depression, anxiety and PTSD. Insomnia is comorbid to migraines, depression, anxiety and PTSD. Migraine and psychiatric disorders negatively impact sleep quality. Also, on the other hand, poor sleep quality predisposes to migraines. Serotonergic dysfunction, HPA axis hyperactivity, hormonal influences, inflammation and sensitisation of the sensory and emotional neural networks are common ingredients to both migraine and psychiatric disorders, such as depression, anxiety and PTSD. Inflammatory markers were found to be elevated in both depression (tumour necrosis factor (TNF) $\alpha, \mathrm{C}$ reactive protein (CRP) and interleukin (IL) 6) and migraine (CRP). ${ }^{84-86}$

Higher frequency and severity of headache seem to correlate with a heavier burden of psychiatric comorbidities. ${ }^{9}$ This dose- 
dependent association is not specific to migraine, but also seems to be present between other chronic pain disorders and psychiatric comorbidities, which raises the question of whether these associations might all, at least partially, be explained by central sensitivity or by neurotransmitter interactions in the trigeminothalamic pathway of migraines. Depression, anxiety, stress, irritability and sleep affect the homeostasis of the transmission of the headache-related nociceptive signals from the thalamus to the cortex (and even prior to the thalamus in the case of serotonin). These signals are affected by different neurotransmitters, including serotonin, noradrenalin and dopamine. In the thalamocortical signal transmission from the thalamus to the cortex, burst discharges are associated with acute pain, whereas tonic discharges are associated with chronic pain. However, additional excitatory inputs can change the firing mode from burst to tonic, and inhibitory input can change the firing mode from tonic to burst. This could explain the impact of psychiatric comorbidities on migraine chronification. ${ }^{87}$

\section{KNOWLEDGE LEARNED FROM IMAGING STUDIES: HOW FUNCTIONAL IMAGING STUDIES MIGHT LEND INSIGHTS INTO SHARED PATHOPHYSIOLOGY BETWEEN MIGRAINE AND PSYCHIATRIC COMORBIDITIES}

Research neuroimaging studies provide insights into the emotional component of migraine symptoms and might provide insights into the comorbidity between migraine and psychiatric disorders. Migraine studies demonstrate abnormal function, structure and connectivity of brain regions that play important roles in determining emotional responses to pain and to other sensory stimuli, and in determining general affect and mood. Greater pain-induced functional activation, and stronger functional connectivity of these regions, likely contribute to determining the emotional aspect of migraine symptoms, and could partially account for the coexistence of psychiatric disorders with migraine.

Affective-motivational brain regions that have been commonly identified as having abnormal function or structure in migraine studies include: anterior cingulate cortex, anterior insula, prefrontal cortex, hippocampus and amygdala. ${ }^{88-100}$ Figure 1 illustrates these brain regions.

Within the realm of a migraine study, atypical structure and function of these regions are usually interpreted as being associated with atypical affective-motivational processing of noxious

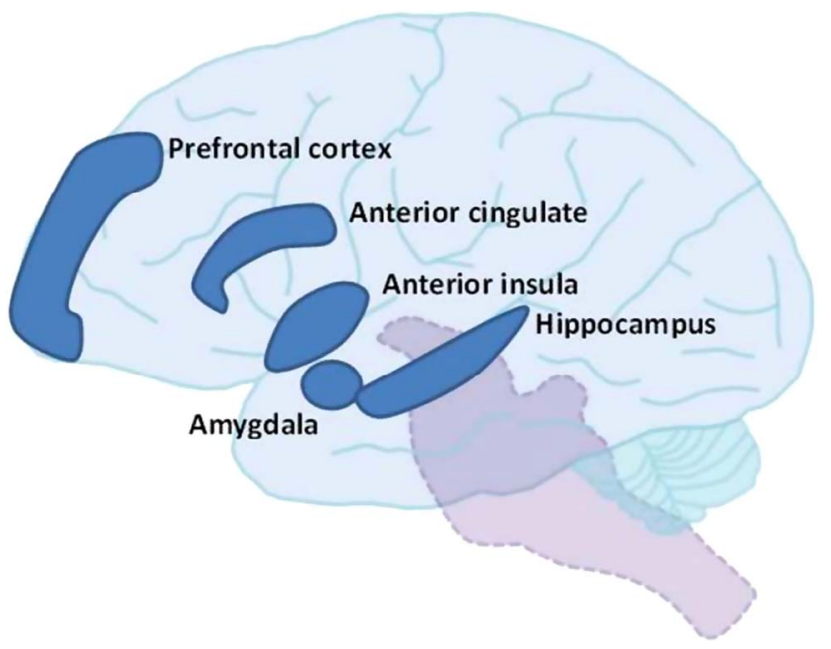

Figure 1 Affective-motivational brain regions commonly identified as having abnormal function or structure in migraine studies. stimuli, including the emotional reactions to migraine headache, lights, sounds and odours. This theory is supported by studies that demonstrate people with migraine tend to have greater activation of affective-motivational brain regions in response to painful stimuli and stronger functional connectivity between affective-motivational brain regions and those regions responsible for sensory-discriminative processing compared with healthy controls. For example, fMRI studies comparing pain-induced brain activation patterns in people with migraine with healthy controls, have demonstrated people with migraine tend to have greater activation in the hippocampus, prefrontal cortex and anterior cingulate cortex, regions that are involved in the emotional responses to pain. ${ }^{89} 90$ Resting-state functional connectivity studies have shown that compared with healthy controls, people with migraine have stronger connectivity between affective-motivational brain regions and those responsible for sensory-discriminative processing. For example, studies demonstrate that people with migraine have stronger connectivity between anterior insula with primary visual cortex, primary auditory cortex and thalamus, and between amygdala with visceroceptive insular cortex, auditory cortex, thalamus and somatosensory cortex. ${ }^{89} 9193$ Stronger functional connectivity could predispose the person with migraine to greater emotional responses to noxious sensory stimuli during the migraine attack. However, since not all migraine studies have matched subject cohorts on measures of anxiety and depression, or excluded participants with psychiatric disorders, it is possible that anxiety and depression are over-represented within these migraine cohorts. This makes it difficult to determine if imaging findings are due to migraine, to psychiatric comorbidity, or to a combination of both. Brain imaging studies of people with psychiatric disorders demonstrate atypical structure and function of similar regions as those identified as being atypical and important for affective-motivational processing of sensory stimuli in migraine studies. ${ }^{101-106}$ Similar to people with depression and other psychiatric disorders, people with migraine have atypical function and structure of brain regions that are important for determining affective-motivational responses to sensory stimuli and for determining mood. ${ }^{100}$ These regions are key components of brain networks implicated in emotion, such as the limbic system, the salience network, and the default mode network. The emotional components of migraine symptoms and the relationships between migraine and comorbid psychiatric disorders might be partially explained by stronger functional activation and connectivity of these brain regions. However, further investigations are required to determine if the atypical imaging findings are a baseline brain trait that predisposes a person to greater emotional responses to painful sensory stimuli as well as to the development of comorbid psychiatric disorders, if they are a result of recurrent migraine attacks that then leads to the development of greater stimulus-induced emotional responses and comorbid psychiatric disease, or if the presence of psychiatric disease leads to changes in these regions that then alter a person's emotional responses to noxious sensory stimuli.

\section{OVERVIEW OF TREATMENT CONSIDERATIONS AND OPTIONS}

Migraine attacks are commonly managed by abortive medications such as triptans and non-steroidal anti-inflammatory drugs. When necessary, preventive medications, such as antidepressants, antihypertensives and antiepileptic drugs, are added to the treatment. ${ }^{107} 108$ Beyond medications, behavioural treatments are often used to treat migraine, and have been found to 
be effective in reducing headache frequency. ${ }^{109}$ Biofeedback, deep breathing, progressive muscle relaxation and guided imagery-coping skills are often used to help patients successfully manage headaches. Additional cognitive strategies often used include cognitive modification, problem-solving techniques, and cognitive-behavioural stress-management therapy. ${ }^{109}$ The combination of medication and behavioural therapy has been found to be more effective than either medication or behavioural therapy alone in treating migraine. ${ }^{34} 37110$

Comorbid psychiatric conditions need to be considered when devising a treatment plan for the patient with migraine. ${ }^{21}{ }^{111-}$ 113 However, many of the treatments listed above are evaluated in samples of patients without comorbid psychiatric illness, limiting our understanding of how these comorbidities impact outcomes of migraine treatment. The literature that does exist on the impact of psychiatric comorbidities on the effectiveness of headache treatment is mixed. Some studies have cited psychiatric comorbidities as a reason for failure of migraine treatment. ${ }^{114-117}$ Other studies have indicated that patients with comorbid psychiatric diagnoses show similar rates of improvement after treatment when compared with patients with no comorbid psychiatric diagnoses. ${ }^{118}$ To date, there is no treatment algorithm for the management of migraine in patients with psychiatric comorbidities. However, a few considerations need to be mentioned.

First, the choice of the migraine-preventive medication in patients with psychiatric comorbidities should be based on psychiatric comorbidity severity, patients' preference, patients' risks for adverse events and prior treatment history. ${ }^{11}$

Second, when the psychiatric comorbidity is mild, monotherapy for migraine prevention and a psychiatric comorbidity can be considered. For example, the migraine preventive propranolol may help with some forms of anxiety. However, when the treatments of the psychiatric comorbidity and migraine do not overlap or the conditions are severe, it is necessary to use separate treatments. ${ }^{119}$ Examples are discussed in table 3.

Using different treatments for migraine and psychiatric comorbidities instead of monotherapy seems to improve outcomes and to minimise side effects. ${ }^{120}$ Medications used for both migraine and psychiatric comorbidities are usually used at different doses with a different titration plan according to the condition they are intended to treat. Treatments should be reviewed independently for their effectiveness on the condition for which they were prescribed (migraine or psychiatric comorbidity), and potential side effects, and drug-drug interactions should be assessed. The treatment plan should be coordinated between all the physicians involved. ${ }^{120}$

Third, the treatment of migraine and the psychiatric comorbidities should be carried out in a sequential stepwise manner with close monitoring of potential side effects and treatment interactions. ${ }^{11}$ Attempts should be made to avoid migraine preventives that can potentially worsen patients' psychiatric comorbidities. For example, the migraine preventive topiramate can affect mood. ${ }^{120}$ The data about a potential association between $\beta$-blockers and depression are controversial and limited. ${ }^{120}$ In the event that someone has a psychiatrist, it is advisable to consider discussing potential risks with the patient's psychiatrist before prescribing migraine-preventive medications.

Behavioural treatments (eg, progressive muscle relaxation, biofeedback, CBT) are effective migraine management options with enduring benefits, and are essentially free of side effects. $^{121} 122$ They may be less costly than pharmacological interventions. $^{123}$ As stated previously, studies have shown that combination pharmacological-behavioural therapy is most effective for migraine treatment. ${ }^{34} 37124125$ Because studies have shown that these American Academy of Neurology/US Headache Consortium level A evidence-based treatments ${ }^{125}$ have a synergistic effect when combined with medications, consider using them in combination with pharmacological treatments for migraine and/or psychiatric comorbidity. A pilot randomised control trial on CBT for comorbid migraine and major depressive disorder suggests at least a 4-month long improvement in headaches, depression, anxiety and quality of life. $^{126}$

Fourth, the development of mood disorder symptoms in episodic patients with migraine who do not require preventive therapy may indicate suboptimal migraine management, in which case the physician should decide whether to start the patient on a preventive therapy or on a mood disorder therapy based on the severity of the emerging psychiatric disorder. ${ }^{120}$

A few studies have been conducted examining how treatment of migraine may impact comorbid psychiatric disorders. A recent pilot study on the effect of onabotulinumtoxin A used for migraine prevention in patients with $\mathrm{CM}$ with comorbid depression and anxiety suggested an improvement in depression and anxiety symptoms measured by the Beck Depression Inventory II, Patient Health Questionnaire 9 and (GAD-7. ${ }^{127}$ However, further studies are needed.

Table 3 Pharmacological treatments used for migraine prevention and psychiatric comorbidities

\begin{tabular}{|c|c|c|}
\hline Treatment & Psychiatric comorbidity use & Migraine prevention effectiveness \\
\hline Tricyclic antidepressants (TCAs), eg, amitriptyline & $\begin{array}{l}\text { Effective for depression at high doses, } \\
\text { with more side effects }\end{array}$ & Effective for migraine prevention at low doses, with minimal side effects \\
\hline $\begin{array}{l}\text { Serotonin-Neuropinephrine Reuptake Inhibitors } \\
\text { (SNRIs), eg, venlafaxine }\end{array}$ & $\begin{array}{l}\text { Effective for depression and decreases } \\
\text { anxiety }\end{array}$ & $\begin{array}{l}\text { Only venlafaxine has grade } B \text { evidence of efficacy for migraine prevention } \\
\text { However, the most recent Cochrane study did not find venlafaxine to be more } \\
\text { effective than placebo for prevention of chronic migraines }{ }^{145}\end{array}$ \\
\hline $\begin{array}{l}\text { Selective Serotonin Reuptake Inhibitors (SSRIs), } \\
\text { eg, fluoxetine }\end{array}$ & Effective for depression & $\begin{array}{l}\text { According to the Cochrane review, SSRIs were not better than placebo for } \\
\text { migraine prevention }\end{array}$ \\
\hline$\beta$-blockers, eg, propranolol & $\begin{array}{l}\text { Might help with anxiety, but might also } \\
\text { worsen depression }\end{array}$ & Effective for migraine prevention \\
\hline \multicolumn{3}{|l|}{ Anticonvulsants } \\
\hline Topiramate & $\begin{array}{l}\text { Might help with mood stabilisation, but } \\
\text { might also worsen depression }\end{array}$ & Effective for migraine prevention \\
\hline Divalproex sodium & $\begin{array}{l}\text { Might help with mood stabilisation, } \\
\text { bipolar disorder }\end{array}$ & Effective for migraine prevention \\
\hline
\end{tabular}




\section{CONCLUSION}

Psychiatric comorbidities have a much higher prevalence in patients with migraine than in the general population, and even more so in patients with CM than in patients with EM. There are hypotheses that could potentially explain the intricate relationships between psychiatric comorbidities but, the biological mechanisms to explain these intricate relationships are still not well understood. Of concern, psychiatric comorbidities seem to increase the risk of development of migraine chronicity, decrease the quality of life of patients with migraine, and complicate migraine management. Since psychiatric comorbidities so intricately affect migraines, their chronicity and their management, it is essential to screen patients with migraine for psychiatric comorbidities. More studies need to be conducted to explicitly address this intersection from a therapeutic point of view given the clinical, functional and cost implications.

Competing interests RL reports grants and personal fees from Alder, personal fees from Allergan, personal fees from CoLucid, grants and personal fees from Electrocore, personal fees and other from eNeura, personal fees from Ethicon, personal fees from Merck, grants and personal fees from Novartis, personal fees from Labrys, personal fees from Autonomic Technologies, personal fees from Boston Scientific, personal fees from Bristol Myers Squibb, personal fees from Dr Reddys, personal fees from Eli Lilly, personal fees from Endo Pharmaceuticals, personal fees from Informa, grants from Migraine Research Fund, grants from National Headache Foundation, grants from NIH, personal fees from Teva, personal fees from Vedanta, outside the submitted work. TJS reports personal fees from Allergan, personal fees from Zogenix, personal fees from Supernus, all outside the submitted work.

Provenance and peer review Not commissioned; externally peer reviewed.

\section{REFERENCES}

1 Lipton RB, Bigal ME, Diamond M, et al. Migraine prevalence, disease burden, and the need for preventive therapy. Neurology 2007;68:343-9.

2 Breslau N, Davis GC. Migraine, physical health and psychiatric disorder: a prospective epidemiologic study in young adults. J Psychiatr Res 1993;27:211-21.

3 Jette N, Pattern S, Williams J, et al. Comorbidity of migraine and psychiatric disorders - a national population-based study. Headache 2008;48:501-16.

4 Lanteri-Minet M, Radat F, Chautard MH, et al. Anxiety and depression associated with migraine: influence on migraine subjects' disability and quality of life, and acute migraine management. Pain 2005;118:319-26.

5 Minen MT, Tanev K. Influence of psychiatric comorbidities in migraineurs in the emergency department. Gen Hosp Psychiatry 2014;36:533-8.

6 Lipton RB, Hamelsky SW, Kolodner KB, et al. Migraine, quality of life, and depression: a population-based case-control study. Neurology 2000;55:629-35.

7 Breslau N, Schultz LR, Stewart WF, et al. Headache and major depression: is the association specific to migraine? Neurology 2000;54:308-13.

8 Zwart JA, Dyb G, Hagen K, et al. Depression and anxiety disorders associated with headache frequency. The Nord-Trondelag health study. Eur J Neurol 2003; 10:147-52.

9 Antonaci F, Nappi G, Galli F, et al. Migraine and psychiatric comorbidity: a review of clinical findings. J Headache Pain 2011;12:115-25.

10 Ashina S, Serrano D, Lipton RB, et al. Depression and risk of transformation of episodic to chronic migraine. J Headache Pain 2012;13:615-24

11 Peck KR, Smitherman TA, Baskin SM. Traditional and alternative treatments for depression: implications for migraine management. Headache 2015;55:351-5.

12 Breslau N. New insights into the comorbidity of migraine and depression. Adv Stud Med 2002;2:754.

13 Baskin SM, Smitherman TA. Migraine and psychiatric disorders: comorbidities, mechanisms, and clinical applications. Neurol Sci 2009;30(Suppl 1):S61-5.

14 Merikangas KR, Angst J, Isler H. Migraine and psychopathology. Results of the Zurich cohort study of young adults. Arch Gen Psychiatry 1990;47:849-53.

15 Merikangas KR, Merikangas JR, Angst J. Headache syndromes and psychiatric disorders: association and familial transmission. J Psychiatr Res 1993;27:197-210.

16 Breslau N, Davis GC, Andreski P. Migraine, psychiatric disorders, and suicide attempts: an epidemiologic study of young adults. Psychiatry Res 1991;37:11-23.

17 Fornaro M, Stubbs B. A meta-analysis investigating the prevalence and moderators of migraines among people with bipolar disorder. J Affect Disord 2015;178:88-97.

18 Gordon-Smith K, Forty L, Chan C, et al. Rapid cycling as a feature of bipolar disorder and comorbid migraine. J Affect Disord 2015;175:320-4.

19 Gigante AD, Barenboim IY, Dias RD, et al. Rapid cycling bipolar disorder is associated with a higher lifetime prevalence of migraine. Acta Psychiatr Scand 2015;132:308-9.
20 Dilsaver SC, Benazzi F, Oedegaard KJ, et al. Is a family history of bipolar disorder a risk factor for migraine among affectively ill patients? Psychopathology 2009;42:119-23.

21 Breslau N. Psychiatric comorbidity in migraine. Cephalalgia 1998;18(Supp 22):56-8; discussion 58-61.

22 Baskin SM, Lipchik GL, Smitherman TA. Mood and anxiety disorders in chronic headache. Headache 2006;46(Suppl 3):S76-87.

23 McWilliams LA, Goodwin RD, Cox BJ. Depression and anxiety associated with three pain conditions: results from a nationally representative sample. Pain 2004;111:77-83.

24 Goulart AC, Santos IS, Brunoni AR, et al. Migraine headaches and mood/anxiety disorders in the ELSA Brazil. Headache 2014;54:1310-19.

25 Smitherman TA, Kolivas ED, Bailey JR. Panic disorder and migraine: comorbidity, mechanisms, and clinical implications. Headache 2013;53:23-45.

26 Pesa J, Lage MJ. The medical costs of migraine and comorbid anxiety and depression. Headache 2004;44:562-70.

27 Minen MT, Seng EK, Holroyd KA. Influence of family psychiatric and headache history on migraine-related health care utilization. Headache 2014;54:485-92.

28 Gonda X, Rihmer Z, Juhasz G, et al. High anxiety and migraine are associated with the s allele of the 5HTTLPR gene polymorphism. Psychiatry Res 2007;149:261-6.

29 Lucchetti G, Peres MF, Lucchetti AL, et al. Generalized anxiety disorder, subthreshold anxiety and anxiety symptoms in primary headache. Psychiatry Clin Neurosci 2013;67:41-9.

30 Dodick DW. Review of comorbidities and risk factors for the development of migraine complications (infarct and chronic migraine). Cephalalgia 2009;29(Suppl 3):7-14.

31 Scher Al, Midgette LA, Lipton RB. Risk factors for headache chronification. Headache 2008;48:16-25.

32 Santos IS, Brunoni AR, Goulart AC, et al. Negative life events and migraine: a cross-sectional analysis of the Brazilian longitudinal study of adult health (ELSA-Brasil) baseline data. BMC Public Health 2014;14:678.

33 Radat F. Stress and migraine. Rev Neurol (Paris) 2013;169:406-12.

34 Holroyd KA, Cottrell CK, O'Donnell FJ, et al. Effect of preventive (beta blocker) treatment, behavioural migraine management, or their combination on outcomes of optimised acute treatment in frequent migraine: randomised controlled trial. BMJ 2010;341:c4871.

35 Holroyd KA, Penzien DB. Pharmacological versus non-pharmacological prophylaxis of recurrent migraine headache: a meta-analytic review of clinical trials. Pain 1990:42:1-13.

36 Hershey AD, Powers SW, Coffey CS, et al. Childhood and adolescent migraine prevention (CHAMP) study: a double-blinded, placebo-controlled, comparative effectiveness study of amitriptyline, topiramate, and placebo in the prevention of childhood and adolescent migraine. Headache 2013;53:799-816.

37 Powers SW, Kashikar-Zuck SM, Allen JR, et al. Cognitive behavioral therapy plus amitriptyline for chronic migraine in children and adolescents: a randomized clinical trial. JAMA 2013;310:2622-30.

38 McEwen BS, Seeman T. Protective and damaging effects of mediators of stress. Elaborating and testing the concepts of allostasis and allostatic load. Ann N Y Acad Sci 1999;896:30-47.

39 Borsook D, Maleki N, Becerra L, et al. Understanding migraine through the lens of maladaptive stress responses: a model disease of allostatic load. Neuron 2012;73:219-34.

40 Tessitore A, Russo A, Esposito F, et al. Interictal cortical reorganization in episodic migraine without aura: an event-related $\mathrm{fMRI}$ study during parametric trigeminal nociceptive stimulation. Neurol Sci 2011;32(Suppl 1):S165-7.

41 Rainero I, Ferrero $\mathrm{M}$, Rubino $\mathrm{E}$, et al. Endocrine function is altered in chronic migraine patients with medication-overuse. Headache 2006;46:597-603.

42 Lipton RB, Buse DC, Hall CB, et al. Reduction in perceived stress as a migraine trigger: testing the "let-down headache" hypothesis. Neurology 2014;82:1395-401.

43 Cattaneo A, Riva MA. Stress-induced mechanisms in mental illness: a role for glucocorticoid signaling. J Steroid Biochem Mol Biol 2015.

44 Tietjen GE, Peterlin BL. Childhood abuse and migraine: epidemiology, sex differences, and potential mechanisms. Headache 2011;51:869-79.

45 Tietjen GE, Buse DC, Fanning KM, et al. Recalled maltreatment, migraine, and tension-type headache: results of the AMPP study. Neurology 2015;84:132-40.

46 Tietjen GE, Brandes JL, Peterlin BL, et al. Childhood maltreatment and migraine (part II). Emotional abuse as a risk factor for headache chronification. Headache 2010;50:32-41.

47 Kuhlman KR, Geiss EG, Vargas I, et al. Differential associations between childhood trauma subtypes and adolescent HPA-axis functioning. Psychoneuroendocrinology 2015;54:103-14.

48 Schreier HM, Enlow MB, Ritz T, et al. Childhood abuse is associated with increased hair cortisol levels among urban pregnant women. J Epidemiol Community Health 2015;69:1169-74.

49 Seng EK, Driscoll MA, Brandt CA, et al. Prescription headache medication in OEF/ OIF veterans: results from the women veterans cohort study. Headache 2013;53:1312-22. 
50 Rao AS, Scher Al, Vieira RV, et al. The impact of post-traumatic stress disorder on the burden of migraine: results from the national comorbidity survey-replication. Headache 2015.

51 Peterlin BL, Tietjen GE, Brandes JL, et al. Posttraumatic stress disorder in migraine. Headache 2009;49:541-51.

52 Muse M. Stress-related, posttraumatic chronic pain syndrome: behavioral treatment approach. Pain 1986;25:389-94.

53 Saunders K, Merikangas K, Low NC, et al. Impact of comorbidity on headache-related disability. Neurology 2008;70:538-47.

54 Kessler RC. Posttraumatic stress disorder: the burden to the individual and to society. J Clin Psychiatry 2000;61(Suppl 5):4-12; discussion 13-14.

55 Peterlin BL, Tietjen G, Meng $\mathrm{S}$, et al. Post-traumatic stress disorder in episodic and chronic migraine. Headache 2008;48:517-22.

56 Peterlin BL, Rosso AL, Sheftell FD, et al. Post-traumatic stress disorder, drug abuse and migraine: new findings from the national comorbidity survey replication (NCS-R). Cephalalgia 2011;31:235-44.

57 Juang KD, Yang CY. Psychiatric comorbidity of chronic daily headache: focus on traumatic experiences in childhood, post-traumatic stress disorder and suicidality. Curr Pain Headache Rep 2014;18:405.

58 Fasmer OB, Halmoy A, Oedegaard KJ, et al. Adult attention deficit hyperactivity disorder is associated with migraine headaches. Eur Arch Psychiatry Clin Neurosci 2011;261:595-602.

59 Rains JC, Poceta JS. Headache and sleep disorders: review and clinical implications for headache management. Headache 2006;46:1344-63.

60 Odegard SS, Engstrom M, Sand T, et al. Associations between sleep disturbance and primary headaches: the third Nord-Trondelag health study. I Headache Pain 2010;11:197-206

61 Kelman L, Rains JC. Headache and sleep: examination of sleep patterns and complaints in a large clinical sample of migraineurs. Headache 2005;45:904-10.

62 Cevoli S, Giannini G, Favoni V, et al. Migraine and sleep disorders. Neurol Sci 2012;33(Suppl 1):S43-6

63 Calhoun $\mathrm{AH}$, Ford S. Behavioral sleep modification may revert transformed migraine to episodic migraine. Headache 2007;47:1178-83.

64 Dosi C, Figura M, Ferri R, et al. Sleep and headache. Semin Pediatr Neurol 2015;22:105-12.

65 Dodick DW, Eross EJ, Parish JM, et al. Clinical, anatomical, and physiologic relationship between sleep and headache. Headache 2003:43:282-92.

66 Langemark M, Olesen J. Drug abuse in migraine patients. Pain 1984;19:81-6.

67 Salomone JA III, Thomas RW, Althoff JR, et al. An evaluation of the role of the ED in the management of migraine headaches. Am J Emerg Med 1994;12:134-7.

68 Tennant FS Jr, Rawson RA. Outpatient treatment of prescription opioid dependence: comparison of two methods. Arch Intern Med 1982;142:1845-7.

69 Swartz KL, Pratt LA, Armenian HK, et al. Mental disorders and the incidence of migraine headaches in a community sample: results from the Baltimore epidemiologic catchment area follow-up study. Arch Gen Psychiatry 2000:57:945-50

70 Zlotnik Y, Plakht Y, Aven A, et al. Alcohol consumption and hangover patterns among migraine sufferers. J Neurosci Rural Pract 2014;5:128-34.

71 Panconesi A. Alcohol and migraine: trigger factor, consumption, mechanisms. A review. J Headache Pain 2008;9:19-27.

72 Trestman RL. DSM-5 and personality disorders: where did axis II go? J Am Acad Psychiatry Law 2014;42:141-5

73 Maizels M. Psychiatric screening for headache patients. Headache 2012;52(Suppl 1):26-9.

74 Maizels $M$, Smitherman TA, Penzien DB. A review of screening tools for psychiatric comorbidity in headache patients. Headache 2006;46(Suppl 3):S98-109.

75 Whooley MA, Avins AL, Miranda J, et al. Case-finding instruments for depression. Two questions are as good as many. J Gen Intern Med 1997;12:439-45.

76 Kroenke K, Spitzer RL, Williams JB. The patient health questionnaire-2: validity of a two-item depression screener. Med Care 2003;41:1284-92.

77 Williams LS, Brizendine EJ, Plue L, et al. Performance of the PHQ-9 as a screening tool for depression after stroke. Stroke 2005;36:635-8.

78 Smitherman TA, Maizels M, Penzien DB. Headache chronification: screening and behavioral management of comorbid depressive and anxiety disorders. Headache 2008;48:45-50.

79 Bigal ME, Serrano D, Buse D, et al. Acute migraine medications and evolution from episodic to chronic migraine; a longitudinal population-based study. Headache 2008:48:1157.

80 Buse DC, Manack A, Serrano D, et al. Sociodemographic and comorbidity profiles of chronic migraine and episodic migraine sufferers. JNNP 2010;81:428-32.

81 Blumenfeld A, Varon S, Wilcox TK, et al. Disability, HRQoL and resource use among chronic and episodic migraineurs: results from the international burden of migraine study (IBMS). Cephalalgia 2011;31:301-15.

82 Smitherman TA, McDermott MJ, Buchanan EM. Negative impact of episodic migraine on a university population: quality of life, functional impairment, and comorbid psychiatric symptoms. Headache 2011;51:581-9.

83 Lipton RB, Silberstein SD. Why study the comorbidity of migraine? Neurology 1994;44(10 Suppl 7):S4-5.
84 Furtado M, Katzman MA. Examining the role of neuroinflammation in major depression. Psychiatry Res 2015;229:27-36.

85 Welch KM, Brandes AW, Salerno L, et al. C-reactive protein may be increased in migraine patients who present with complex clinical features. Headache 2006;46:197-9.

86 Vanmolkot FH, de Hoon JN. Increased C-reactive protein in young adult patients with migraine. Cephalalgia 2007;27:843-6.

87 Noseda R, Kainz V, Borsook D, et al. Neurochemical pathways that converge on thalamic trigeminovascular neurons: potential substrate for modulation of migraine by sleep, food intake, stress and anxiety. PLOS ONE 2014;9:e103929.

88 Schwedt TJ, Chong CD, Chiang CC, et al. Enhanced pain-induced activity of pain-processing regions in a case-control study of episodic migraine. Cephalalgia 2014;34:947-58.

89 Tso AR, Trujillo A, Guo CC, et al. The anterior insula shows heightened interictal intrinsic connectivity in migraine without aura. Neurology 2015;84:1043-50.

90 Russo A, Tessitore A, Esposito F, et al. Pain processing in patients with migraine: an event-related fMRI study during trigeminal nociceptive stimulation. J Neurol 2012;259:1903-12.

91 Hadjikhani N, Ward N, Boshyan J, et al. The missing link: enhanced functional connectivity between amygdala and visceroceptive cortex in migraine. Cephalalgia 2013:33:1264-8.

92 Jin C, Yuan K, Zhao L, et al. Structural and functional abnormalities in migraine patients without aura. NMR Biomed 2013;26:58-64.

93 Schwedt TJ, Schlaggar BL, Mar S, et al. Atypical resting-state functional connectivity of affective pain regions in chronic migraine. Headache 2013;53:737-51.

94 Xue T, Yuan K, Cheng P, et al. Alterations of regional spontaneous neuronal activity and corresponding brain circuit changes during resting state in migraine without aura. NMR Biomed 2013;26:1051.

95 Zhao L, Liu J, Dong $X$, et al. Alterations in regional homogeneity assessed by fMRI in patients with migraine without aura stratified by disease duration. I Headache Pain 2013; $14: 85$

96 Xue T, Yuan K, Zhao L, et al. Intrinsic brain network abnormalities in migraines without aura revealed in resting-state fMRI. PLOS ONE 2012;7:e52927.

97 Yu D, Yuan K, Zhao L, et al. Regional homogeneity abnormalities in patients with interictal migraine without aura: a resting-state study. NMR Biomed 2012;25:806-12.

98 Niddam DM, Lai KL, Fuh JL, et al. Reduced functional connectivity between salience and visual networks in migraine with aura. Cephalalgia 2015.

99 Valfrè W, Rainero I, Bergui M, et al. Voxel-based morphometry reveals gray matter abnormalities in migraine. Headache 2008:48:109-17.

100 Schwedt TJ, Chong CD. Functional imaging and migraine: new connections? Curr Opin Neurol 2015;28:265-70

101 Schmaal L, Veltman DJ, van Erp TG, et al. Subcortical brain alterations in major depressive disorder: findings from the ENIGMA major depressive disorder working group. Mol Psychiatry 2015.

102 Córdova-Palomera A, Tornador C, Falcón C, et al. Altered amygdalar resting-state connectivity in depression is explained by both genes and environment. Hum Brain Mapp 2015;36:3761-76.

103 Iwabuchi SJ, Krishnadas R, Li C, et al. Localized connectivity in depression: a meta-analysis of resting state functional imaging studies. Neurosci Biobehav Rev 2015;51:77-86

104 Harrison BJ, Fullana MA, Soriano-Mas C, et al. A neural mediator of human anxiety sensitivity. Hum Brain Mapp 2015;36:3950-8.

105 Alvarez RP, Kirlic N, Misaki M, et al. Increased anterior insula activity in anxious individuals is linked to diminished perceived control. Trans/ Psychiatry 2015;5: e591.

106 Poletti S, Radaeili D, Cucchi M, et al. Neural correlates of anxiety sensitivity in panic disorder: a functional magnetic resonance imaging study. Psychiatry Res 2015;233:95-101.

107 Couch JR. Prophylactic pharmacotherap. In: Olesen J, Tfelt-Hansen P, Welch MA, eds. The headaches. New York: Raven Press, Ltd, 1993.

108 Hershey AD. Current approaches to the diagnosis and management of paediatric migraine. Lancet Neurol 2010;9:190-204.

109 Blanchard EB. Psychological treatment of benign headache disorders. J Consult Clin Psychol 1992;60:537-51.

110 Matchar DB, Harpole L, Samsa GP, et al. The headache management trial: a randomized study of coordinated care. Headache 2008:48:1294-310.

111 Breslau N, Merikangas K, Bowden CL. Comorbidity of migraine and major affective disorders. Neurology 1994;44(10 Suppl 7):S17-22.

112 Breslau N, Lipton RB, Stewart WF, et al. Comorbidity of migraine and depression: investigating potential etiology and prognosis. Neurology 2003;60:1308-12.

113 Merikangas KR, Stevens DE. Comorbidity of migraine and psychiatric disorders. Neurol Clin 1997;15:115-23.

114 Lake AE III. Behavioral and nonpharmacologic treatments of headache. Med Clin North Am 2001;85:1055-75.

115 Lipchik GL, Penzien DB. Psychiatric comorbidities in patients with headache. Sem Pain Med 2004;2:93-105. 
116 Lipton RB, Silberstein SD, Saper JR, et al. Why headache treatment fails. Neurology 2003;60:1064-70.

117 Penzien DB, Rains J, Holroyd KA. Psychological assessment of the recurrent headache sufferer. In: Tollison C, Kunkel R, eds. Headache: diagnosis and treatment. Baltimore, MD: Williams and Wilkins, 1993:39-49.

118 Heckman BD, Holroyd KA, Himawan L, et al. Do psychiatric comorbidities influence headache treatment outcomes? Results of a naturalistic longitudinal treatment study. Pain 2009;146:56-64.

119 Finocchi C, Villani V, Casucci G. Therapeutic strategies in migraine patients with mood and anxiety disorders: clinical evidence. Neurol Sci 2010;31(Suppl 1): S95-8.

120 Silberstein SD, Dodick D, Freitag F, et al. Pharmacological approaches to managing migraine and associated comorbidities-clinical considerations for monotherapy versus polytherapy. Headache 2007;47:585-99.

121 Campbell J, Penzien D, Wall E. Evidence-based guidelines for migraine headache: behavioral and physical treatments. 1999. http://tools.aan.com/professionals/ practice/pdfs/gl0089.pdf

122 Andrasik F, Blanchard EB, Neff DF, et al. Biofeedback and relaxation training for chronic headache: a controlled comparison of booster treatments and regular contacts for long-term maintenance. J Consult Clin Psychol 1984;52:609-15.

123 Schafer AM, Rains JC, Penzien DB, et al. Direct costs of preventive headache treatments: comparison of behavioral and pharmacologic approaches. Headache 2011;51:985-91.

124 Wallasch TM, Angeli A, Kropp P. Outcomes of a headache-specific cross-sectional multidisciplinary treatment program. Headache 2012;52:1094-105.

125 Silberstein SD. Practice parameter: evidence-based guidelines for migraine headache (an evidence-based review): report of the quality standards subcommittee of the American academy of neurology. Neurology 2000;55:754-62.

126 Martin PR, Aiello R, Gilson K, et al. Cognitive behavior therapy for comorbid migraine and/or tension-type headache and major depressive disorder: an exploratory randomized controlled trial. Behav Res Ther 2015;73:8-18.

127 Boudreau GP, Grosberg BM, McAllister PJ, et al. Prophylactic onabotulinumtoxin A in patients with chronic migraine and comorbid depression: an open-label, multicenter, pilot study of efficacy, safety and effect on headache-related disability, depression, and anxiety. Int J Gen Med 2015;9:79-86.

128 Tietjen GE, Brandes JL, Peterlin BL, et al. Childhood maltreatment and migraine (part I). Prevalence and adult revictimization: a multicenter headache clinic survey. Headache 2010;50:20-31.

129 Edmeads J, Lainez JM, Brandes JL, et al. Potential of the migraine disability assessment (MIDAS) questionnaire as a public health initiative and in clinical practice. Neurology 2001;56(6 Suppl 1):S29-34.
130 Stewart WF, Lipton RB, Kolodner KB, et al. Validity of the migraine disability assessment (MIDAS) score in comparison to a diary-based measure in a population sample of migraine sufferers. Pain 2000;88:41-52.

131 Snaith RP, Zigmond AS. The hospital anxiety and depression scale. BMJ (Clin Res Ed) $1986 ; 292: 344$

132 Zigmond AS, Snaith RP. The hospital anxiety and depression scale. Acta Psychiatr Scand 1983;67:361-70.

133 Beck AT, Steer RA, Ball R, et al. Comparison of beck depression inventories -IA and -II in psychiatric outpatients. J Pers Assess 1996;67:588-97.

134 Reiss S, Peterson RA, Gursky DM, et al. Anxiety sensitivity, anxiety frequency and the prediction of fearfulness. Behav Res Ther 1986;24:1-8.

135 Lowe B, Decker O, Muller S, et al. Validation and standardization of the generalized anxiety disorder screener (GAD-7) in the general population. Med Care 2008;46:266-74.

136 Beck AT, Epstein N, Brown G, et al. An inventory for measuring clinical anxiety: psychometric properties. J Consult Clin Psychol 1988;56:893-7.

137 Hirschfeld RM. The mood disorder questionnaire: a simple, patient-rated screening instrument for bipolar disorder. Prim Care Companion J Clin Psychiatry 2002:4:9-11.

138 Hirschfeld RM, Williams JB, Spitzer RL, et al. Development and validation of a screening instrument for bipolar spectrum disorder: the mood disorder questionnaire. Am J Psychiatry 2000;157:1873-5.

139 Consoli SM, Taine P, Szabason F, et al. Development and validation of a perceived stress questionnaire recommended as a follow-up indicator in occupational medicine. Encephale 1997;23:184-93.

140 Wacogne C, Lacoste JP, Guillibert E, et al. Stress, anxiety, depression and migraine. Cephalalgia 2003;23:451-5.

141 Backhaus J, Junghanns K, Broocks A, et al. Test-retest reliability and validity of the Pittsburgh sleep quality index in primary insomnia. J Psychosom Res 2002;53:737-40.

142 Bastien $\mathrm{CH}$, Vallieres A, Morin CM. Validation of the insomnia severity index as an outcome measure for insomnia research. Sleep Med 2001;2:297-307.

143 Blake DD, Weathers FW, Nagy LM, et al. The development of a clinician-administered PTSD scale. J Trauma Stress 1995;8:75-90.

144 Silberstein SD, Holland S, Freitag F, et al. Evidence-based guideline update: pharmacologic treatment for episodic migraine prevention in adults: report of the quality standards subcommittee of the American Academy of Neurology and the American Headache Society. Neurology 2012;78:1337-45.

145 Banzi R, Cusi C, Randazzo C, et al. Selective serotonin reuptake inhibitors (SSRIs) and serotonin-norepinephrine reuptake inhibitors (SNRIs) for the prevention of tension-type headache in adults. Cochrane Database Syst Rev 2015;5:CD011681. 